\title{
Deriva Simulada de Formulações Comerciais de Glyphosate SOBRE MARACUJAZEIRO AMARELO
}

\author{
Drift Simulation of Glyphosate Commercial Formulations on Yellow Passion Fruit Growth
}

\author{
WAGNER JÚNIOR, A. ${ }^{2}$, TUFFI SANTOS, L.D. ${ }^{3}$, SANTOS, C.E.M. ${ }^{4}$, SILVA, J.O.C. ${ }^{5}$, PIMENTEL, \\ L.D. ${ }^{6}$, BRUCKNER, C.H. ${ }^{7}$ e FERREIRA, F.A. ${ }^{7}$
}

\begin{abstract}
RESUMO - Objetivou-se com este trabalho avaliar os efeitos da deriva de formulações comerciais de glyphosate no desenvolvimento de plantas jovens de maracujazeiro amarelo. O trabalho foi realizado em casa de vegetação do Departamento de Fitotecnia da Universidade Federal de Viçosa, durante o período de março a abril de 2007. Foi utilizado o delineamento experimental de blocos casualizados, em esquema fatorial $3 \times 4+1$, em que três foram as formulações de glyphosate e cinco foram as doses utilizadas acrescidas de testemunha sem herbicida. O trabalho foi conduzido com cinco repetições, sendo cada planta considerada como parcela experimental. As formulações comerciais aplicadas foram Roundup Transorb ${ }^{\circledR}$, Roundup Original ${ }^{\circledR}$ e Zapp QI ${ }^{\circledR}$, utilizando-se as seguintes doses (g e.a ha ${ }^{-1}$ ): 43,2; 86,4; 172,8; e 345,6 $\mathrm{g} \mathrm{ha}^{-1}$. Aos 28 dias após a aplicação (DAA), avaliaram-se os comprimentos da parte aérea, da raiz e total $(\mathrm{cm})$; o diâmetro do caule $(\mathrm{mm})$; o número de folhas e de ramificações primárias; a massa seca da parte aérea e da raiz das plantas (g); e a área foliar por planta $\left(\mathrm{cm}^{2}\right)$. Aos 7, 14 e 28 DAA, avaliou-se, visualmente, a porcentagem de intoxicação das plantas. O glyphosate em deriva simulada, independentemente das formulações utilizadas, ocasionou injúrias no maracujazeiro amarelo, acarretando redução no crescimento e desenvolvimento das plantas. As formulações Roundup Transorb ${ }^{\circledR}$ e Roundup Original ${ }^{\circledR}$ foram mais prejudiciais às plantas que o Zapp Qi ${ }^{\circledR}$. O maracujazeiro amarelo mostrou-se suscetivel à deriva, devendo o glyphosate ser usado com cuidado, de maneira a atingir somente as plantas daninhas a serem controladas.
\end{abstract}

Palavras-chave: fitointoxicação, herbicida, plantas daninhas, Passiflora spp.

\begin{abstract}
The aim of this work was to evaluate the effects of drift simulation of commercial formulations of glyphosate on the growth of young plants of yellow passion fruit. The work was carried out at the Plant Science Department of the Universidade Federal de Viçosa (MG), Brazil, from March to April 2007. The experiment was arranged in a completely randomized block design, with five replications, in a factorial $3 \times 4+1$, consisting of three glyphosate formulations and five doses, (one being the control without herbicide). Each plot was constituted by one plant. The applied doses of glyphosate were 43.2; 86.4; 172.8 and $345.6 \mathrm{~g} \mathrm{ha}^{-1}$, using the commercial

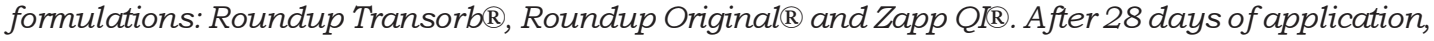
aerial part, root and total length $(\mathrm{cm})$, stem diameter $(\mathrm{mm})$, number ofleaves and primary ramifications, aerial part and root dry mass, (g) and the foliar area per plant $\left(\mathrm{cm}^{2}\right)$ were evaluated. After 7,14 and 28 application days, intoxication percentage of the plants was also evaluated. Regardless of the formulations used, glyphosate drift simulation caused injury to the yellow passion fruit, reducing

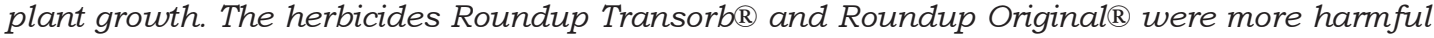
than Zapp Qi®. The yellow passion fruit was susceptible to drift simulation; thus, glyphosate must be used carefully, so as to reach only the weeds to be controlled.
\end{abstract}

Keywords: plant intoxication, herbicide, yellow passion fruit, weeds, Passiflora spp.

1 Recebido para publicação em 10.12.2007 e na forma revisada em 28.6.2008.

2 Engo-Agró-, D.Sc., Professor Adjunto do Dep. de Horticultura, Universidade Tecnológica Federal do Paraná - Campus Dois Vizinhos-PR, 85660-000, <americowagner@utfpr.edu.br>; ${ }^{3}$ Eng $^{\circ}-$ Agr $^{\circ}$, D.Sc. Prof. Adjunto do Instituto de Ciências Agrárias da UFMG, Av. Osmani Barbosa, s/n - Bairro JK, Caixa Postal 135 39404-006, Montes Claros-MG; ${ }^{4}$ Engo-Agr ${ }^{\circ}$, Pós-Doutorando em Fitotecnia, UFV. Bolsista FAPEMIG; ${ }^{5}$ Eng $^{-0}{ }^{-A g r}{ }^{0}$, Mestrando em Fitotecnia, UFV; ${ }^{6}$ Eng $^{0}$-Agr ${ }^{\circ}$, Doutorando em Fitotecnia, UFV, ${ }^{7}$ Eng-ô-Agr $^{0}$, D.Sc., Prof. Titular do Dep. de Fitotecnia, UFV. Av. P. H. Rolfs, sn, 36570-000 Viçosa-MG.

Planta Daninha, Viçosa-MG, v. 26, n. 3, p. 677-683, 2008 


\section{INTRODUÇÃO}

O Brasil é o maior produtor mundial de maracujá, tendo produzido, em 2004, 491.619 t, com rendimento médio de $13.441 \mathrm{~kg} \mathrm{ha}^{-1}$ (IBGE, 2006). O termo maracujá refere-se, normalmente, às espécies de Passiflora que produzem frutos comestiveis, como Passiflora edulis, $P$. quadrangularis, $P$. alata, $P$. ligularis, P. mollisima, $P$. cincinnata, $P$. nitida e $P$. rubra. No Brasil, predominam os cultivos de Passiflora edulis (maracujá-amarelo) e, em menor escala, Passiflora alata (maracujá-doce).

O manejo integrado de plantas daninhas é considerado uma das práticas mais importantes no cultivo de maracujá-amarelo, uma vez que, se mal manejadas, as plantas daninhas podem acarretar sérios prejuizos à produtividade do pomar.

O maracujazeiro amarelo apresenta sistema radicular axial superficial (CarvalhoOkano \& Vieira, 2001), concentrando-se principalmente nos primeiros $0,20 \mathrm{~m}$ do solo, de modo que a planta pode facilmente ser prejudicada pela presença de plantas daninhas, devido à competição por nutrientes e água, reduzindo conseqüentemente a produção por planta. Devido à localização superficial do sistema radicular do maracujazeiro amarelo, a adoção do controle químico por meio de herbicidas é uma prática promissora, uma vez que os outros métodos podem danificar as raízes, prejudicando o desenvolvimento da planta e facilitando a entrada de patógenos do solo, como Fusarium oxysporum f.s. passiflorae (Bruckner \& Picanço, 2001).

Um dos herbicidas mais utilizados na fruticultura é o glyphosate, sendo recomendada sua aplicação em culturas como citros, macieira, videira, ameixeira, nectarineira, pessegueiro, bananeira, cacaueiro e pereira (Amarante Júnior et al., 2002). O glyphosate atua sobre a atividade enzimática da 5-enolpiruvil shiquimato-3-fosfato sintase (EPSPS), inibindo a síntese dos aminoácidos aromáticos triptofano, tirosina e fenilalanina (Kruze et al., 2000; Trezzi et al., 2001). Esse produto caracteriza-se por ser um produto sistêmico, nãoseletivo e seu uso é considerado de baixo impacto ambiental. Contudo, para a cultura do maracujazeiro amarelo, ainda não existem herbicidas registrados pelo Ministério da
Agricultura, Pecuária e Abastecimento (MAPA) e são escassas as pesquisas envolvendo esse assunto.

Apesar disso, o glyphosate é usado tanto no início da formação do pomar de maracujazeiro amarelo como na sua condução. Esse fato pode ser de grande risco para a cultura, em razão do aparecimento de intoxicações e conseqüente morte das plantas no pomar, principalmente nas fases iniciais da cultura, situação em que as plantas são aparentemente mais suscetíveis à intoxicação por esse herbicida.

Por meio da simulação da deriva de diferentes formulações de herbicidas, como o glyphosate, pode-se avaliar esse efeito sobre plantas jovens de maracujazeiro amarelo num possivel contato indesejado com esses produtos. Entre as formas de contato estão a deriva e o contato direto da calda no momento da aplicação dirigida do glyphosate no controle de plantas daninhas no próprio pomar e a deriva proveniente de áreas tratadas no entorno do cultivo. O contato indesejado do glyphosate, quando aplicado de forma dirigida, com a cultura de interesse é freqüente, o que tem justificado a realização de estudos sobre deriva simulada de glyphosate e seus efeitos no crescimento e desenvolvimento de plantas como eucalipto (Tuffi Santos et al., 2005), milho (Magalhães et al., 2001), pessegueiro (Tuffi Santos et al., 2006) e algodoeiro (Miller et al., 2004; Yamashita \& Guimarães, 2005).

Objetivou-se com este trabalho avaliar os efeitos da deriva de formulações comerciais de glyphosate sobre o crescimento de plantas jovens de maracujazeiro amarelo.

\section{MATERIAL E MÉTODOS}

O trabalho foi realizado em casa de vegetação do Departamento de Fitotecnia da Universidade Federal de Viçosa, durante o período de março a abril de 2007. Foram utilizadas plantas jovens de maracujazeiro amarelo, cultivadas em recipientes plásticos de $3 \mathrm{~L}(0,32 \times 0,16 \mathrm{~m})$, contendo como substrato a mistura de Latossolo Vermelho + areia $2: 1 \mathrm{v} / \mathrm{v}$, enriquecido com $\mathrm{P}_{2} \mathrm{O}_{5}\left(3,0 \mathrm{~kg} \mathrm{~m}^{-3}\right)$.

O delineamento experimental empregado foi o de blocos casualizados, em esquema 
fatorial $3 \times 4+1$, em que três foram as formulações de glyphosate e cinco foram as doses utilizadas acrescidas de testemunha sem herbicida. O trabalho foi conduzido com cinco repetições, sendo cada planta considerada como parcela experimental. As formulações comerciais aplicadas foram Roundup Transorb ${ }^{\circledR}$, Roundup Original ${ }^{\circledR}$ e Zapp QI ${ }^{\circledR}$, utilizando-se as seguintes doses (g e.a ha ${ }^{-1}$ ): 43,2; 86,4; 172,8; e 345,6 $\mathrm{g} \mathrm{ha}^{-1}$.

Todas as aplicações de herbicidas foram realizadas sobre as plantas de maracujazeiro amarelo quando estas atingiram, em média, $0,30 \mathrm{~m}$ de altura. Para isso, foi utilizado pulverizador costal com pressão constante mantida por $\mathrm{CO}_{2}$ pressurizado, munido de barra com duas pontas de aplicação tipo leque, modelo TT 110.02 , operando a $250 \mathrm{kPa}$ de pressão e volume de calda de $150 \mathrm{~L} \mathrm{ha}^{-1}$. A pulverização foi direcionada sobre as mudas, simulando deriva, de modo a não atingir o terço superior das plantas. Após a aplicação, evitou-se o contato das folhas do maracujá com a água proveniente da irrigação ou da chuva, prevenindo a possivel lavagem dos produtos.

Aos 7, 14 e 28 dias após a aplicação (DAA), avaliou-se, visualmente, a porcentagem de intoxicação das plantas por glyphosate em relação ao controle sem herbicida, atribuindo-se notas que variaram entre 0 e $100 \%$, em que $0 \%$ correspondeu à ausência de sintomas visiveis e $100 \%$ à morte das plantas (Frans, 1972). Aos 28 DAA, avaliaram-se os comprimentos da parte aérea, da raiz e total $(\mathrm{m})$; o diâmetro do caule $(\mathrm{mm})$; o número de folhas e de ramificações primárias; a massa seca da parte aérea e da raiz das plantas (g); e a área foliar por planta $\left(\mathrm{cm}^{2}\right)$.

Para determinação do comprimento da parte aérea, da raiz e total das plantas, elas foram retiradas dos substratos, cuidadosamente lavadas em água e medidas com auxílio de uma régua graduada em centímetros. Na obtenção dos dados de diâmetro do caule foi utilizado paquímetro digital graduado em milimetros, na altura do colo das plantas. O sistema radicular e a parte aérea foram secos em estufa de circulação forçada a $60{ }^{\circ} \mathrm{C}$, até atingirem massa constante, obtida em 72 horas, para posterior determinação do valor da massa da matéria seca do sistema radicular e da parte aérea, sendo realizada a pesagem em balança analítica.
O comprimento da parte aérea e o diâmetro do caule, obtidos no início do experimento, foram subtraídos pelo valor obtido aos 28 DAA, determinando-se os ganhos em altura e o crescimento em diâmetro por planta após a exposição à deriva. Para determinação da área foliar $\left(\mathrm{cm}^{2}\right)$, as folhas de cada planta foram digitalizadas, e as fotos, analisadas no programa computacional Image Pro-plus.

Os dados foram submetidos à análise de variância e as médias comparadas a $5 \%$ pelo teste de Tukey para o fator qualitativo, bem como à análise de regressão, para o fator quantitativo, por meio do programa computacional SANEST (Zonta \& Machado, 1984). Os dados de porcentagem de intoxicação foram transformados previamente em arco seno $\sqrt{\mathrm{x} / 100}$, e o número de folhas e de ramificações primárias, em $\sqrt{\mathrm{x}+1}$.

\section{RESULTADOS E DISCUSSÃO}

As plantas de maracujazeiro amarelo apresentaram sintomas de intoxicação, como murcha, clorose e necrose, e morte dos ápices, sintomas típicos de intoxicação por glyphosate, os quais foram verificados a partir dos 7 DAA, sendo mais pronunciados na maior dose aplicada (345,6 $\mathrm{g} \mathrm{ha}^{-1}$ de glyphosate) (Figura 1A, B, C). A mudança na coloração da folha pode estar relacionada à degeneração dos cloroplastos, observada por Campbell et al. (1976) em plantas tratadas com glyphosate, ou aos efeitos deste herbicida sobre a inibição da formação de clorofila, descrita por Cole et al. (1983). Os mesmos sintomas foliares foram observados em outras culturas submetidas à deriva simulada com glyphosate, como eucalipto (Tuffi Santos et al., 2005), milho (Magalhães et al., 2001), pessegueiro (Tuffi Santos et al., 2006) e algodoeiro (Miller et al., 2004; Yamashita \& Guimarães, 2005).

As doses de glyphosate tiveram influência significativa $(p<0,01)$ sobre a intoxicação das plantas aos 7 DAA (Figura 1A), 14 DAA (Figura 1B) e 28 DAA (Figura 1C), não sendo observado efeito estatístico para a formulação comercial de glyphosate aplicada, nem para a interação de ambos (formulação de glyphosate $\mathrm{x}$ dose).

Planta Daninha, Viçosa-MG, v. 26, n. 3, p. 677-683, 2008 

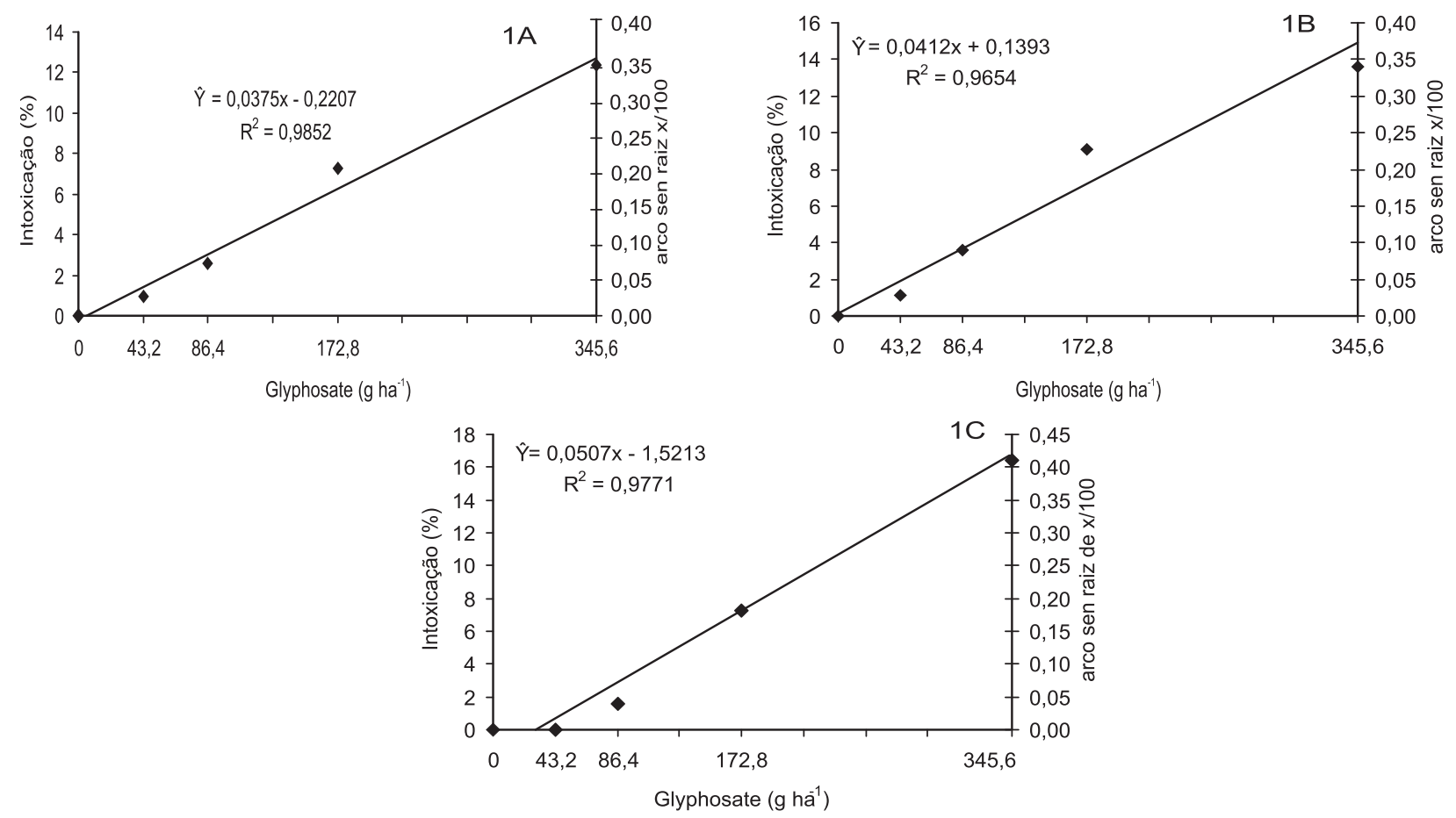

Figura 1 - Porcentagem de intoxicação das plantas jovens de maracujazeiro amarelo submetidas à deriva do glyphosate, aos 7 (A), 14 (B) e 28 dias (C) após aplicação. Viçosa-MG, 2007.

Observou-se na Figura 1A, B, C comportamento linear crescente, com aumento na porcentagem de intoxicação das plantas de maracujazeiro amarelo à medida que foram submetidas às maiores doses de glyphosate, em todas as épocas de avaliação.

Houve significância para número de brotações primárias, comprimento total, massa seca da parte aérea e área foliar quando da aplicação de glyphosate. Contudo, para o comprimento de raiz, as dose de glyphosate aplicadas foram semelhantes entre si (Figura 2A, B, C, D e E). Por outro lado, as formulações comerciais de glyphosate, nas doses aplicadas, e a interação dos dois fatores não afetaram o diâmetro do caule e o número de folhas de plantas jovens de maracujazeiro amarelo.

O número de brotações primárias aumentou linearmente à medida que houve aumento nas doses de glyphosate (Figura 2A). Esse fato pode estar relacionado à morte do meristema apical das plantas, em decorrência das doses aplicadas, inibindo o crescimento vertical e estimulando o desenvolvimento lateral com o surgimento do maior número de brotações primárias. Dantas et al. (2001) e Tuffi Santos et al. (2005), trabalhando com glyphosate em eucalipto, também relataram o surgimento de brotações laterais juntamente com os sintomas de intoxicação pelo herbicida.

A interrupção do crescimento apical teve reflexos no comprimento total das plantas de maracujazeiro amarelo em decorrência da aplicação das maiores doses de glyphosate (Figura 2B). De acordo com Thomas et al. (2005), entre as injúrias visuais provocadas por herbicidas está o atraso no desenvolvimento das plantas.

As plantas jovens, conforme aumentam seu tamanho, gradualmente assumem sua forma típica e alcançam o equilíbrio na razão parte aérea/parte subterrânea. Todavia, se houver alguma mudança drástica nas condições de cultivo, a correlação logarítmico-linear existente entre a massa do caule e a massa da raiz ('crescimento alométrico') pode ser alterada (Larcher, 2000).

Para massa seca da parte aérea (Figura 2D) e área foliar (Figura 2E), observouse efeito quadrático das diferentes doses de glyphosate sobre as plantas, com pontos 

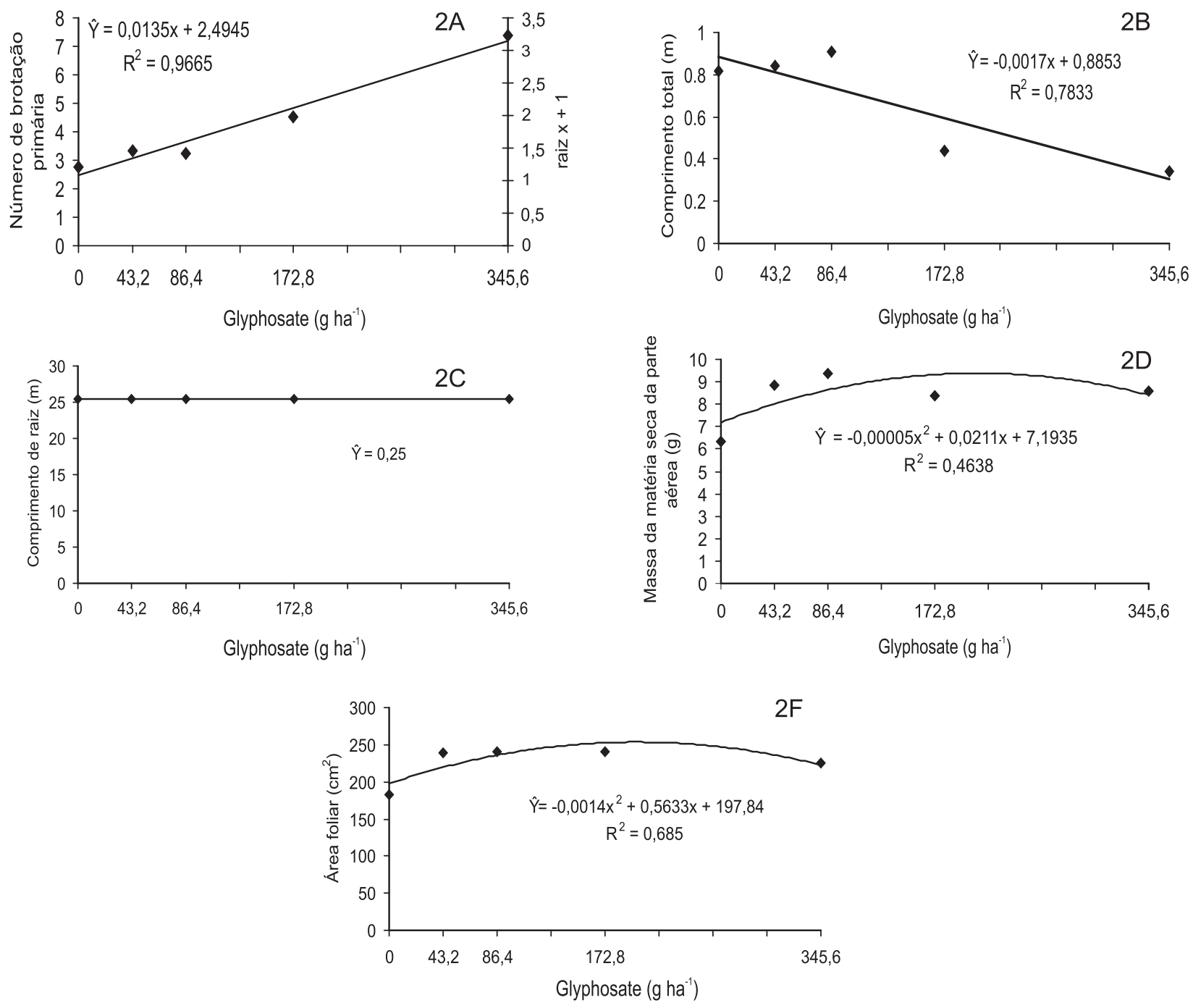

Figura 2 - Número de brotações primárias (A), comprimento total (B), massa seca da parte aérea (D) e área foliar (E) de plantas jovens de maracujazeiro amarelo submetidas à deriva do glyphosate. Viçosa-MG, 2007.

estimados de máximo quando da aplicação das doses de 211 e $201,18 \mathrm{~g} \mathrm{ha}^{-1}$ de glyphosate, respectivamente. Provavelmente, pode ter havido acréscimo da área foliar em resposta aos danos causados pelo glyphosate até o ponto de máximo. Esse acréscimo pode ter permitido aumento na taxa fotossintética, refletindo acréscimos na quantidade de matéria seca, em proporção semelhante ao aumento verificado na área foliar (Figura 2D, E).

Quanto ao comprimento da parte aérea do maracujazeiro amarelo, verificou-se efeito significativo na interação glyphosate $\mathrm{x}$ dose, observando-se comportamento linear decrescente para todas as formulações comerciais de glyphosate com o aumento nas doses aplicadas (Figura 3). Resultados semelhantes foram obtidos por Yamashita \& Guimarães (2006), analisando a deriva simulada com glyphosate em algodoeiro.

Acredita-se que a maior intoxicação aliada à morte do ápice das plantas jovens de maracujazeiro amarelo possam explicar o menor comprimento da parte aérea à medida que se aumentaram as doses aplicadas de glyphosate.

Nas três formulações comerciais de glyphosate aplicadas, constataram-se diferenças significativas em comprimento total, massa seca da raiz e área foliar das plantas jovens de 


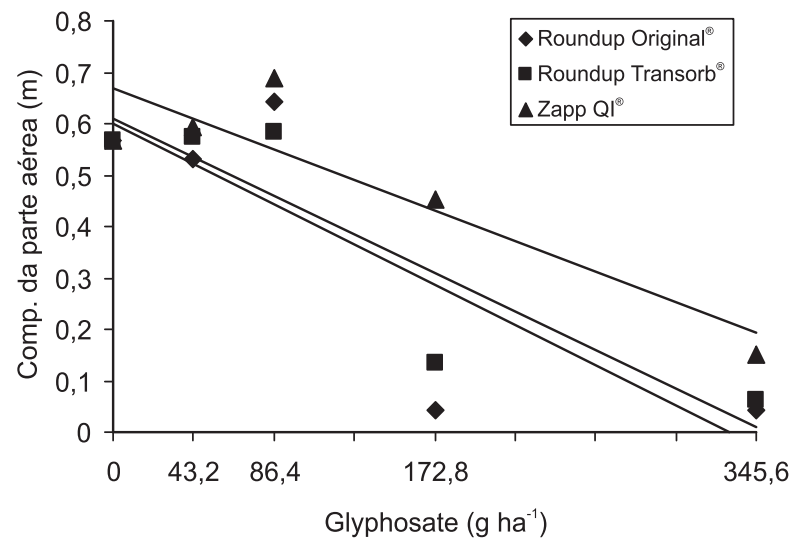

Figura 3 - Comprimento da parte aérea de plantas jovens de maracujazeiro amarelo submetidas à deriva do glyphosate. Roundup Original $^{\circledR}\left(\mathrm{v}=-0,0018 \mathrm{x}+0,6014 ; \mathrm{R}^{2}=0,70\right)$, Roundup Transorb $^{\circledR}\left(\mathrm{v}=-0,0017 \mathrm{x}+0,6083 ; \mathrm{R}^{2}=0,81\right) \mathrm{e}$ Zapp QI ${ }^{\circledR}\left(\mathrm{v}=-0,0014 \mathrm{x}+0,6677 ; \mathrm{R}^{2}=0,81\right)$. Viçosa-MG, 2007

maracujazeiro amarelo (Tabela 1). Verificouse que a formulação comercial Zapp QI ${ }^{\circledR}$ foi a que apresentou as maiores médias para área foliar, comprimento total e massa seca da raiz, com exceção destas duas últimas variáveis, que não diferiram estatisticamente do Roundup Transorb ${ }^{\circledR}$.

Existem disponibilizadas no mercado várias formulações de glyphosate, que possuem em sua composição diferentes tipos de sais (Rodrigues \& Almeida, 2005). Entre os sais utilizados na formulação de glyphosate têm-se: o sal potássico $\left(Z a p p\right.$ Qi $\left.{ }^{\circledR}\right)$, o sal de isopropilamina (Roundup Transorb ${ }^{\circledR}$ e Roundup Original ${ }^{\circledR}$ ) e o sal amônio (Werlang et al., 2003). Segundo Molin \& Hirase (2005), uma das particularidades de cada formulação inclui a maior velocidade de translocação e de ação na planta, o que pode explicar o comportamento diferenciado de algumas características do maracujazeiro amarelo quando submetidas à deriva de diferentes formulações.

O Roundup Transorb ${ }^{\circledR}$ e o Roundup Original ${ }^{\circledR}$ apresentam maior velocidade de absorção e translocação em relação ao Zapp Qi ${ }^{\circledR}$ (Santos et al., 2007). Assim, é possivel que plantas expostas ao Roundup Transorb ${ }^{\circledR}$ e Roundup Original ${ }^{\circledR}$ possam ter seu desenvolvimento mais afetado, como pôde ser verificado pelas menores médias obtidas para comprimento total, massa seca da raiz e área foliar.
Tabela 1 - Comprimento total, massa seca da raiz e área foliar das plantas jovens de maracujazeiro amarelo submetidas à deriva, utilizando três formulações comerciais de glyphosate. Viçosa-MG, 2007

\begin{tabular}{|l|c|c|c|}
\hline $\begin{array}{c}\text { Formulação comercial } \\
\text { de Glyphosate }\end{array}$ & $\begin{array}{c}\text { Comp. total } \\
(\mathrm{m})\end{array}$ & $\begin{array}{c}\text { Massa seca } \\
\text { da raiz }(\mathrm{g})\end{array}$ & $\begin{array}{c}\text { Área foliar } \\
\left(\mathrm{cm}^{2}\right)\end{array}$ \\
\hline Roundup Original $^{\circledR}$ & $0,62 \mathrm{~b} *$ & $2,13 \mathrm{~b}$ & $221,14 \mathrm{~b}$ \\
\hline Roundup Transorb $^{\circledR}$ & $0,64 \mathrm{ab}$ & $2,49 \mathrm{ab}$ & $212,42 \mathrm{~b}$ \\
\hline Zapp $\mathrm{QI}^{\circledR}$ & $0,74 \mathrm{a}$ & $2,84 \mathrm{a}$ & $243,60 \mathrm{a}$ \\
\hline $\mathrm{CV}(\%)$ & 21,74 & 29,67 & 14,39 \\
\hline
\end{tabular}

* Médias seguidas pela mesma letra na coluna não diferem entre si a $5 \%$ de probabilidade pelo teste de Tukey.

Concluiu-se que o glyphosate em deriva simulada, independentemente das formulações utilizadas, ocasionou injúrias no maracujazeiro amarelo, reduzindo o crescimento e desenvolvimento das plantas, devendo, portanto, ser adotadas medidas que evitem o contato do produto com as plantas da cultura. As formulações Roundup Transorb ${ }^{\circledR}$ e Roundup Original ${ }^{\circledR}$ foram mais prejudiciais ao maracujazeiro amarelo que o Zapp $\mathrm{Qi}^{\circledR}$, considerando as variáveis comprimento total da planta, massa seca da raiz e área foliar.

\section{LITERATURA CITADA}

AMARANTE JÚNIOR, O. P. et al. Glifosato: propriedades, toxicidade, usos e legislação. Química Nova, v. 25, n. 4 , p. $589-593,2002$.

BRUCKNER, C. H.; PICANÇO, M. C. (Eds.) Maracujá: tecnologia de produção, pós-colheita, agroindústria. Porto Alegre: Cinco Continentes, 2001. 465 p

CAMPBELL, W. F.; EVANS, J. O.; REED, F. C. Effect of glyphosate on chloroplast ultrastructure of quack grass mesophyll cell. Weed Sci., v. 24, p. 22-25, 1976.

CARVALHO-OKANO, R. M.; VIEIRA, M. F. Morfologia externa e taxionomia. In: BRUCKNER, C. H.; PICANÇO, M. E. (Eds.) Maracujá: tecnologia de produção, póscolheita, agroindústria. Porto Alegre: Cinco Continentes, 2001. p.33-49.

COLE, D. J.; CASELEY, J. C.; DODGE, A. D. Influence of glyphosate on selected plant process. Weed Res., v. 23, p. $173-183,1983$.

DANTAS, F. W. F.; SOUZA, A. J.; CIERO, A. D. Controle da rebrota de eucalipto em área de reflorestamento. In: SEMINÁRIO NACIONAL SOBRE HERBICIDAS E TECNOLOGIA DE APLICAÇÃO EM FLORESTAS, 2001, Viçosa-MG. Anais... Viçosa, MG:SBS/SIF, 2001. p. 29-44. 
FRANS, R. E. Measuring plant responses. In: WILKINSON, R. E. (Ed.) Research methods in weed science. Champaign: Southern Weed Science Society, 1972. p. $28-41$.

\section{INSTITUTO BRASILEIRO DE GEOGRAFIA E}

ESTATISTICA - IBGE. Indicadores: produção agrícola. Disponível em: <http://www.ibge.gov.br.> Acesso em: 23 de nov. de 2006

KRUSE, N. D.; TREZZI, M. M.; VIDAL, R. A. Herbicidas inibidores da EPSPS: revisão de literatura. R. Bras. Herbic., v. 1, n. 2, p. 139-146, 2000.

LARCHER, W. Ecofisiologia vegetal. São Carlos: Rima, 2000. $531 \mathrm{p}$

MAGALHÃES, P. C. et al. Efeito de doses reduzidas de glyphosate e paraquat simulando deriva na cultura do milho. Planta Daninha, v. 19, n. 2, p. 247-253, 2001

MILLER, D. K. et al. Response of non glyphosate resistant cotton to reduced tates of glyphosate. Weed Sci., v. 52, p. $178-182,2004$

MOLIN, W. T.; HIRASE, K. Effects of surfactants and simulated rainfall on the efficacy of the Engane formulation of glyphosate in johnsongrass, prickly sida and yellow nutsedge. Weed Biol. Manag., v. 5, p. 123-127, 2005.

RODRIGUES, B. N.; ALMEIDA, F. S. Guia de herbicidas. 5.ed. Londrina: Grafmarke, 2005. 591 p.
SANTOS, J. B. et al. Avaliação de formulações de glyphosate sobre soja Roundup Ready. Planta Daninha, v. 25, n. 1, p. 165-171, 2007.

THOMAS, W. E. et al. Yield and physiological response of nontransgenic cotton to simulated glyphosate drift. Weed Technol., v. 19, p. 35-42, 2005

TREZZI, M. M.; KRUZE, N. D.; VIDAL, R. A. Inibidores de EPSPS. In: VIDAL, R.A.; MEROTTO JR., A. (Eds.).

Herbicidologia. Porto Alegre: 2001. p. 37-45.

TUFFI SANTOS, L. D. et al. Deriva de herbicidas e efeito de fungicida $\mathrm{x}$ herbicida em plantas jovens de pessegueiro. Planta Daninha, v. 24, n. 3, p. 505-512, 2006

TUFFI SANTOS, L. D. et al. Crescimento e morfoanatomia foliar de eucalipto sob efeito de deriva do glyphosate. Planta Daninha, v. 23, n. 1, p. 133-142, 2005.

WERLANG, R. C. et al. Efeitos da chuva na eficiência de formulações e doses de glyphosate no controle de Brachiaria decumbens. Planta Daninha, v. 21, n. 1, p. 121-130, 2003.

YAMASHITA, O. M; GUIMARÃES, S. C. Deriva simulada de glyphosate em algodoeiro: efeito de dose, cultivar e estádio de desenvolvimento. Planta Daninha, v. 24, n. 4 , p. $821-826,2006$.

YAMASHITA, O. M.; GUIMARÃES, S. C. Resposta de cultivares de algodoeiro a subdoses de glyphosate. Planta Daninha, v. 23, n. 4, p. 627-633, 2005.

ZONTA, E. P.; MACHADO, A. A. SANEST - Sistema de Análise Estatística para Microcomputadores. Pelotas: Universidade Federal de Pelotas, 1984. 75 p. 